\title{
Síndrome de Beckwith-Wiedeman en Tres Hermanas
}

\author{
Dr. Carlos Almazán A. 1, Dra Margarita Jullían P. 1, \\ Dr. Wenceslao Aranda R.2 \\ Beckwi th-Wiedeman Syndrome in Three Sisters
}

The ocurrence of Beckwith--Wiedeman Syndrome in three sisters from the same mother and different father is reported. Two of them were twins and died in early infancy. The third one is now 12 years old and with the exception of Beckwith-Wiedeman Syndrome features she is healthy. The possible dominant autosomic nature of the syndrome is discussed.

En el año 1963 Beckwith ${ }^{1}$ comunicó por primera vez los resultados de la necropsia de tres niños con onfalocele, macroglosia muscular e hipertrofia de varios órganos, atribuyendo su fallecimiento a hipoglicemia neonata $l^{2}$. Posteriormente han aparecido numerosas publicaciones extranjeras $^{3-4}$ y nacionales ${ }^{5-6}$, en las cuales se plantea con mayor claridad uth cuadro clínico definido, manteniéndose aứn en discusión su tipo de herencia.

1 Médicos pediatras. Hospital Infantil Exequiel González Cortés.

2 Becario de Pediatría. Departamento de Pediatría y Cirugía Infantil Sur. Facultad de Medicina. Universidad de Chile. Hospital Exequiel González Cortés.
En esta oportunidad se presentan tres casos de ocurrencia familiar y se discute su probable mecanisno de transmisión genética.

\section{Casos Clínicos}

Se presentan tres hermanas, dos de ellas gemelas, hijas de la misma madre y distinto padre, todos sanos, y sin antecedentes familiares de casos similares a los que se relatan. No había consanguinidad entre la madre y los padres, ni parentezco entre estos últimos. La madre fue el producto de un embarazo de término, con peso de nacimiento de $3.500 \mathrm{~g}$., período de reciên nacido normal y examen físico sin alteraciones. La genealogía correspondiente se observa en la Figura 1. 


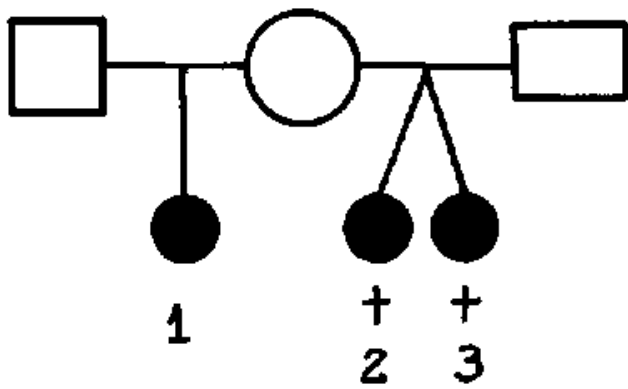

Figura 1. Genealogía de los casos presentados.

Caso 1: C.M.P. sexo femenino, nacida el 9.8 .1981 , pesó 4.850 g. $y$ su talla fue de $52 \mathrm{~cm}$., período neonatal sin complicaciones. A los cinco años de edad fue sontetida a reducción quirúrgica de la lengua para corregir macroglosia. No ha tenido evidencia de cardioparía congénita. A los 12 años tenia rasgos faciales toscos con nariz bastante ancha, mentón prominente, leve exoftalmos, fisuras lineales en los lóbulos de ambos pabellones auriculares, manos y pies grandes. CI 90 (Figura 2).

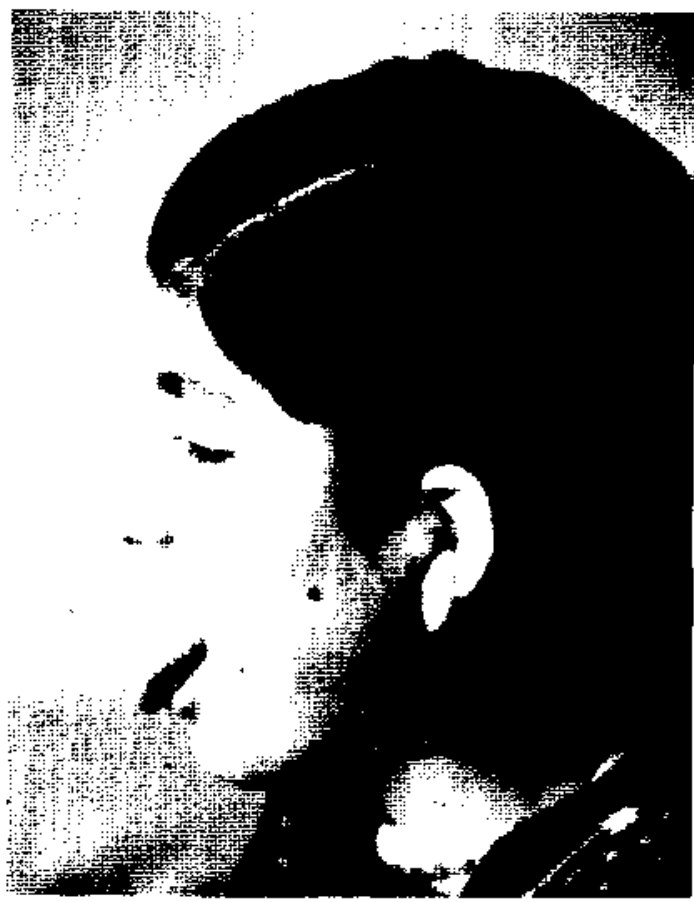

Jigurs 2. (ass) b, rasgos faciales loscos. lengua prominente, lóbulo de la oreja con fisuras lineales.

Caso 2: R.Q.P. sexo femenino, racida el 24.2 .1983 producto de embarazo geme lar, parto de térnino, gemelo Il, peso de nacimiento 2.780 g. Occipucio prominente, orejas de implantación baja, fisura lineales en ambos lóbulos, gran ma. croglosia, soplo cardiaco sistólico $3 / 6$, hepatome- galia y hernia umbilical reductible. Desde su nacimiento sufría crisis de hipoglicemia y signos de insuficiencia card íaca originada en un ducturs arterioso persistente, a lo que se agregó bronconeumonia, falleciendo a los 58 días de vida. En vida se descartó presencia de hipotiroidismo (T3, $T 4$, TSH y edad osea normales).

Caso 3: N.Q.P. sexo femenino, nacida el 24.2.1983, gemelo I del caso anterior, peso de nacimiento $3.180 \mathrm{~g}$. talla $48 \mathrm{~cm}$. Occipucio prominente, micrognatia, macroglosia, fisuras en los lóbulos de ambas orejas y hernia umbilical reductible. Durante el período de recién nacido sufrió episodios de hipoglicemia. Dada de alta a los 53 días de vida reingresó 20 días más tarde por bronconeumonia que le provocó la muerte. En vida se descartó cardiopatía congénita e hipo. tiroidismo (Figuras 3 y 4 ).

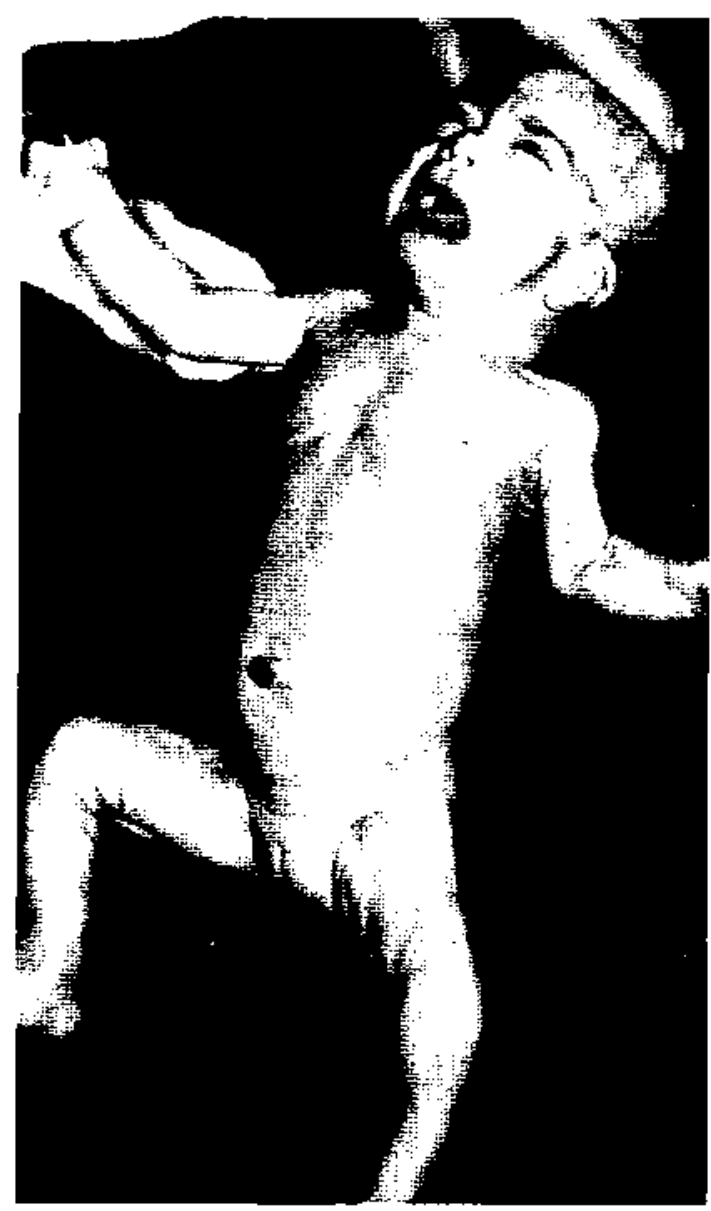

Figura 3. Caso 3, pabellones auriculares de implantación baja, macroglosia, hemia umbilical. 


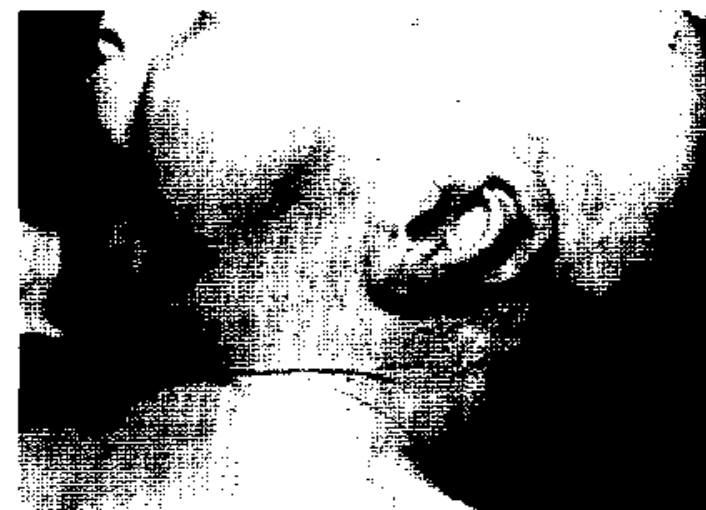

Figura 4. Caso 3, detalle de la cara resaltando la macroglosia, occipucio prominente $y$ fisuras lineales del lóbulo de la oreja.

En ambos casos las necropsias confirmaron los hallazgos clínicos, encontrándose además hepatomegalia. Nu se realizaron estudios histológicos.

\section{COMENTARIO}

El diagnóstico de estos tres casos surge del antecedente de peso de nacimiento aumentado $(4.850 \mathrm{~g}$. en el caso $1,2.780 \mathrm{~g}$. y $3.180 \mathrm{~g}$. en los $\operatorname{casos} 2$ y 3 respectivamente, considerando el carácter gemelar de los dos últimos), las crisis hipoglicémicas en el período de recién nacido, el fenotipo con rasgos toscos y grandes, macroglosia, fisuras en los lóbulos de las orejas, hernia umbilical y otros, en niños en que se descartaron enfermedades como el Sindrome de Sotos (gigantismo cerebral) e hipotiroidismo congénito. En general hay consenso en que las características de este síndrome son bastante flexibles, sin embargo, los hallazgos más frecuentes serian onfalocele o hernia umbilical, macrosomia o gigantismo post-natal, macroglosia, visceromegalia e hipoglicemia neonatal, esta última, presente en el $50 \%$ de los niños. Lo anterior, y resultado de las autopsias de los dos casos fatales, aún cuando no se hicieron estudios histológicos permiten plantear con razonable seguridad el diagnóstico de síndrome de Beckwith-Wiedeman.

El tipo de herencia de este sindrome ha sido motivo de discusión: los primeros informes de Wiedeman ${ }^{3}$ en tres hermanos y de Irving ${ }^{4}$ en dos hermanos y un primo, sugerían transmisión autosómica recesiva. Posteriormente varios autores, entre ellos Kossef 7 presentaron genealogías que orientaban hacia herencia autosómica dominante. Algunos años después este mismo autor ${ }^{8}$, invocó el concepto de premutación, para explicar los hallazgos en algunas familias. Sommer, citado en Mc Kusic ${ }^{9}$ describe tres hermanass sanas que tuvieron a un total de ocho niños aquejados por el sindrome, interpretando la herencia como autosómica dominante con el fenómeno de mutación retardada. En la misma obra se cita un informe de Puissan sobre una familia de seis hermanos (dos de ellos gemelos) cuyos padres eran sanos y no consanguíneos. Finalmente Best y Hoekstra (en Mc Kusick), presentaron una familia al parecer variable.

La genealogía de nuestros pacientes es similar a la descrita por Sommer y Puissan, vale decir recurrencia en hermanos hijos de padres sanos no consanguineos; la madre tiene antecedentes de peso de nacimiento adecuado, no presentó hipoglicemia neonatal y sus rasgos fenotípicos son normales, to que hace poco probable que se trate de herencia autosómica dominante con expresivi. dad variable, aún cuando ésta no se puede descartar. Otra explicación para la genealogía de los casos presentados sería suponer una herencia autosómica dominante con un fenómeno de premutación o de mutación retardada, dependiente de la madre, por ser ella el progenitor común.

No obstante ya sea que se trate de expresividad variable, de premutación o de mutación retardada parecia corresponder a un tipo de herencia autosómica dominante y por lo tanto su riesgo de recurrencia sería de $50 \%$.

\section{RESUMEN}

Se presentan los casos clínicos de tres hermanas, dos de ellas gemelas, fallecidas a corta edad y una tercera hermana de doce años de edad procedentes de embarazos de la misma madre con diferentes padres. Los tres casos presentan rasgos sugerentes del Síndrome de BeckwithWiedeman. Se discuten algunos hechos de la transmisión genética de este cuadro.

\section{REFERENCIAS}

1 Beckwith, J.B.: Extreme cytomegaly of the adrenal fetal cortex, omphalocele, hiperplasia of kidneys and pancreas and Leydig-cell hiperplasia another syndrome? . Presented at annual meeting of Westem Society for Pediatric Research, Los Angeles Calif. Nov. 11, 1963.

${ }^{2}$ Beckwith, J.B.: "Macroglosia, omphalocele, adrenai cy tomegaly, gigantisn. and hyperplastic visceromegaJy" Birth Defects: Original Article Series, Baitimore. Vol. V (2): 188, 1969.

${ }^{3}$ Wiedemon, H.R.: Complexe mal formatif familial avec hernie ombilicale et macroglossic, un "Syndrome Nouveau" J. Genet. hum. 13: 223, 1964.

4 Irving. $U .:$ Exomphalos with macroglosia: a study of 11 cases. J. Pediat. Surg. 2: 499, 1967.

5 Mene, $M$, Strickeler, A.: Sindrome de Wiede$m$ an-Beckwith (macroglosia-onfalocele-macrosomia). Rev. Chil. Pediatr. 50 (1): 59, 1979.

${ }^{6}$ Aspillaga, M., Avendaño, I. Morizon, G., Mosca, V., Biancani. F.: Syndrome de Wiedeman-Beckwith. Rev. 
Chil, Pediatr. 48: 183. 1977.

${ }^{7}$ Kosseff, A.L., Hermann, J. and Opitz, J.M.: The Wicdeman-Beckwith Syndrome: genetic consideration and diagnostic sign (letter) Lancet: 844 only, 1972.

${ }^{8}$ Kosseff, A.L., Herrmann, J., Gilbert, E.F. Videskal,
C., Lubinsky, M. and Opirz, J.M.: The Wiedernan Beckwith Syndrome Europ. J. Pediatr. 123: 139, 1976.

${ }^{9}$ Mc Kusick, V.A.: Mendelian Inheritance in Man. 6th cd., Baltimore, London p. 155, 156. 